\title{
DETERMINANTES DE LA DEMANDA POTENCIAL DE MICROCRÉDITO EN ARGENTINA*
}

\author{
Ignacio E. Carballo** \\ Martin Grandes ${ }^{* *+2 k}$ \\ Luis Molouny $y^{* * * * *}$
}

* doi: 10.11144/Javeriana.cao29-52.cddp. Este artículo es producto de la investigación “¿Cuáles son los determinantes de la demanda potencial de microcrédito en Argentina?", financiado por la Pontificia Universidad Católica Argentina y el Consejo Nacional de Investigaciones Científicas y Técnicas (CONICET), desde marzo de 2013 hasta julio de 2016. El artículo se recibió 19/01/2016 y se aprobó el 30/04/2016. Sugerencia de citación: Carballo, I.; Grandes, M. y Molouny, L. (2016). Determinantes de la demanda potencial de microcrédito en Argentina. Cuadernos de Administración, 29 (52), 199-228. http://dx.doi.org/10.11144/ Javeriana.cao29-52.cddp.

* * Master Internacional en Microfinanzas para el Emprendimiento de la Universidad Autónoma de Madrid, España, 2016. Docente Pontificia Universidad Católica Argentina (UCA) y becario en el Centro de Innovación de los Trabajadores (CITRA-CONICET) de la Universidad Metropolitana por la Educación y el Trabajo (UMET), Buenos Aires, Argentina.

Correo electrónico: nachocarballo4@hotmail.com

*** Docteur en Sciences Economiques de l'École des Hautes Études en Sciences Sociales, Paris, Francia, 2004. Docente Pontificia Universidad Católica Argentina (UCA) y Director de Desarrollo Institucional e Investigador del CONICET del Centro para la Innovación de los Trabajadores de la Universidad Metropolitana por la Educación y el Trabajo (UMET), Ciudad Autónoma de Buenos Aires, Argentina.

Correo electrónico: grandes.m@umet.edu.ar

**** Especialización en Finanzas Avanzadas de la Universidad Católica Argentina, Buenos Aires, Argentina, 2010. Investigador de la Escuela de Negocios de la Universidad Católica Argentina, Buenos Aires, Argentina.

Correo electrónico: luismolouny@yahoo.com 


\section{Determinantes de la demanda potencial de microcrédito en Argentina}

\section{RESUMEN}

Este artículo identifica los determinantes socio-económicos y demográficos de la demanda potencial de microcréditos en Argentina utilizando técnicas de estimación tipo Logit con base en una encuesta aleatoria, estratificada y no proporcional realizada sobre 5.700 hogares en 20 sectores urbanos. Se corren dos regresiones, una para la demanda de microcréditos con fines productivos y otra para la demanda de microcréditos para mejorar o ampliar la vivienda. Se encuentra que el tipo de empleo, la informalidad laboral, la edad, el estado civil y la reincidencia en el endeudamiento son los determinantes de la probabilidad de solicitar un microcrédito para ambos fines. Futuras investigaciones podrían réplica esta metodología para distintos periodos del tiempo con el objeto de brindar robustez a nuestros resultados.

Palabras clave: microfinanzas, encuesta de la deuda socia argentina, determinantes de demanda de microcrédito.

Clasificación JEL: $\mathrm{C}_{25}, \mathrm{G}_{21}, \mathrm{O}_{16}$

\section{Determinants of the potential demand for microcredit in Argentina}

Determinantes da demanda potencial de microcrédito na Argentina

\section{ABSTRACT}

This paper identifies the socio-economic and demographic determinants of the potential demand for microcredits in Argentina using Logit type estimation techniques based on a random, stratified and non-proportional survey covering 5.700 households in 20 urban sectors. The paper runs two regressions, one for the demand for microcredit with productive purposes and another for the demand for microcredit to improve or enlarge housing. It is concluded that the type of employment, labor informality, age, marital status and debt reoccurrence are determinants of the probability to apply for a microcredit for both purposes. Future research could replicate this methodology for different time periods to strengthen our results.

Keywords: microfinances, survey of the Argentinian social debt, determinants of the demand for microcredit.

JEL Classification: $\mathrm{C}_{25}, \mathrm{C}_{21}, \mathrm{O}_{16}$

\section{RESUMO}

Este artigo identifica os determinantes socioeconômicos e demográficos da demanda potencial de microcréditos na Argentina utilizando técnicas de estimativa tipo Logit com base numa pesquisa aleatória, estratificada e não proporcional realizada sobre 5.700 lares em 20 setores urbanos. Realizam-se duas regressões, uma para a demanda de microcréditos com fins produtivos e outra para a demanda de microcréditos para melhorar ou ampliar a moradia. Constatou-se que o tipo de emprego, a informalidade trabalhista, a idade, o estado civil e a reincidência no endividamento são os determinantes da probabilidade de solicitar um microcrédito para ambos os fins. Futuras pesquisas poderiam replicar esta metodologia para diferentes períodos do tempo com o objetivo de dar força a nossos resultados.

Palavras-chave: microfinanças, pesquisa da dívida social argentina, determinantes de demanda de microcrédito. Classificação JEL: C25, G21, O16 


\section{Introducción}

El crédito para vivienda al igual que el crédito productivo incrementan el empleo, la inversión, la productividad y la tasa de crecimiento de la economía a largo plazo, y bajo ciertas condiciones contribuyen a mitigar la pobreza al fomentar la igualdad de oportunidades, suavizar el consumo en el tiempo, y permitir la reasignación de recursos. En este sentido, las microfinanzas han demostrado constituir un mecanismo eficaz de reducción de la pobreza y ser una herramienta de fomento a la inclusión social, aunque no sean una condición suficiente para alcanzar esos objetivos (Morduch, 1998; Quibria, 2012; Banerjee et al., 2013; Cull, 2014).

Los sectores de menores ingresos, al poseer empleos más precarios o inestables, no contar con garantías, y tener mayor vulnerabilidad ante la inflación y otras condiciones de inestabilidad macroeconómica, suelen quedar relegados del acceso al crédito. De hecho, las microfinanzas nacieron en respuesta a la falta de acceso a servicios financieros presente en millares de personas excluidas del sistema financiero formal (Helms, 2006)

Desde la perspectiva de Argentina, si comparamos la experiencia reciente con la de otros países de la región, nos encontramos con que el sector microfinanciero argentino se encuentra en un estado incipiente. Esto es, subdesarrollado y principalmente limitado al microcrédito (BID, 2006; The EconomistIntelligence Unit, 2010; Reed 2011; Grandes, 2014).

Esta característica es motivada por la existencia de ciertos obstáculos tanto a la expansión de la oferta como de la demanda. Entre los principales limitantes se encuentran a nuestro entender: los problemas de información asimétrica, la falta de fondeo a las instituciones que otorgan microcréditos (IMFs de aquí en adelante), el tratamiento impositivo discriminatorio a los microprestatarios informales, los elevados costos laborales que enfrentan las IMFs, la escasa o nula regulación de las entidades que operan en el sector, la ausencia de colateral o garantías en los demandantes y los altos costos operativos que enfrentan las IMFs al monitorear los préstamos (Zander, 1994; Foltz, 2004; Guirkinger et al., 2007; Crouzel, 2009; Grandes et al., 2010).

Por otro lado, cabe aclarar que la información existente sobre el verdadero tamaño del mercado microfinanciero argentino es escasa o nula. Esto es debido, entre otras razones, a un limitado conocimiento de la demanda local. Si bien otros estudios han intentado aportar datos sobre la misma, se encuentran desactualizados o discontinuados en el 
tiempo y presentan ciertas deficiencias metodológicas (PNUD, 2005; Navajas y Tejerina, 2006; Curat, Lupano y Gineste, 2006) ${ }^{1}$.

A su vez, un problema central del mercado microfinanciero en Argentina es que en numerosas ocasiones la falla de las IMFs se debió a la falta de conocimiento de la demanda potencial que enfrentaban (Grandes, 2014).

En términos generales, las microfinanzas se presentan como una herramienta para ofrecer distintos beneficios financieros a la población en situación de pobreza sin colateral. Por un lado, con acceso a préstamos en pequeña escala busca liberar el potencial emprendedor de los pobres económicamente activos e impulsar sus negocios. A través de seguros a medida, les permite proteger sus ganancias en caso de enfermedad u otros imprevistos. Con cuentas de depósitos para facilitar el ahorro, fomenta la suavización del consumo y brinda certeza frente a la volatilidad del emprendimiento. Además, se han desarrollado créditos para vivienda, sistemas de trasferencias y otros servicios financieros innovadores para incluir a los más desfavorecidos (CGAP, 2009; Armendáriz y Morduch, 2010).

En este trabajo definiremos al demandante potencial de un microcrédito (nuestra población objetivo) como aquel individuo de bajos ingresos, generalmente informal o no registrado que manifiesta positivamente su propensión a endeudarse en los próximos doce meses (Navajas y Tejerina, 2006). A su vez, entendemos que dicho demandante se encontrará condicionado a su status ocupacional, socio-educativo, etc. Dichos condicionamientos serán fácilmente diferenciables según la encuesta que utilizamos en nuestro trabajo, la Encuesta de la Deuda Social de la Pontificia Universidad Católica Argentina (en adelante EDSA) ${ }^{2}$.

Con este contexto, los objetivos de la presente investigación son:

1) Identificar y estimar los determinantes de la probabilidad de demandar un microcrédito en el futuro (o propensión a endeudarse) de la población objetivo.

1 Impulso Argentino (2014), organismo dependiente del Ministerio de Economía de la Nación en Argentina, realizó una estimación y caracterización de la demanda potencial de microcréditos. Dicho trabajo es distinto al presente. Difiere en objetivo y utiliza una definición distinta de microcrédito y microprestatario, además no analiza los factores determinantes de la demanda ni estima ningún modelo econométrico.

2 Ver la metodología, cuestionarios e historia de esta encuesta en: http://www.uca.edu.ar/index.php/site/ index/es/uca/observatorio-de-la-deuda-social-argentina/encuesta-de-la-deuda-social/ 
2) Dar cuenta de en qué medida las características socio-económicas y demográficas de las personas influyen en dicha propensión, ya sea para fines productivos o de vivienda.

Nuestra contribución se centra en tres aspectos: primero, a nuestro conocimiento, ofrecemos el primer estudio sobre los determinantes de la demanda prospectiva de microcréditos en Argentina utilizando técnicas de estimación binaria (Logit) con datos de encuestas exhaustivas y con amplia cobertura de los centros urbanos del país. Segundo, explicamos el comportamiento prospectivo de dicha demanda, en contraste con la abrumadora mayoría de la literatura que se centra en la demanda pasada o el acceso a servicios financieros, incluyendo los microcréditos. Y tercero, a diferencia de la literatura precedente, separamos la demanda potencial de microcréditos productivos de aquellos microcréditos para vivienda. Esto último se fundamenta en la vasta demanda insatisfecha de microcréditos para vivienda observada en Argentina (Carballo et al., 2015).

Para ello, estudiamos la demanda potencial de microcréditos en Argentina durante el periodo 2011. Dicho año fue el único en el cual la EDSA incorporó un módulo de inclusión financiera con preguntas prospectivas sobre demandas crediticias diferenciadas por fines (productivo, consumo y vivienda) y para el cual disponemos de nuestra base de datos representativa a nivel país ${ }^{3}$.

Nuestra población objetivo, los demandantes potenciales de microcrédito o individuo con propensión a endeudarse serán aquellos individuos que declararon haber percibido hasta dos salarios mínimos a valores de 2011. Esto es congruente con Navajas y Tejerina (2006) quienes definen la población sujeto de microcréditos a aquella por debajo de un ingreso equivalente a una línea de pobreza. La línea de pobreza es muy cercana al salario mínimo en el caso de Argentina.

Sin embargo, dado el contexto inflacionario en el país, preferimos ser conservadores y utilizar dos salarios mínimos como una medida proxy del ingreso individual, ampliando así el universo propuesto por Navajas y Tejerina con el objeto de tener una aproximación más fiel a la realidad local. De igual modo, en los estratos de ingreso menores a uno o dos salarios mínimos, el ingreso del individuo coincide con el del hogar excepto por los subsidios o planes sociales.

3 De cara a futuras investigaciones restará reproducir en otros periodos de tiempo el ejercicio de la presente investigación con el fin de verificar en qué medida la coyuntura afecta el poder explicativo de las características individuales en nuestro modelo. 
El trabajo se organiza de la siguiente manera: exponemos los antecedentes relevantes en la literatura. Luego, caracterizamos la demanda potencial mediante distintos atributos socio-económico-demográficos utilizando los datos de la EDSA 2011, y finalmente el nivel de bancarización o acceso a servicios financieros bancarios. Posteriormente, realizamos un estudio econométrico de tipo Logit para analizar la probabilidad condicional de dicha demanda respecto de las características mencionadas. Finalmente, presentamos las conclusiones del estudio.

Debemos destacar que mediante nuestra caracterización descriptiva y las estimaciones econométricas subsiguientes, pretendemos verificar las siguientes hipótesis:

a) La demanda potencial de microcrédito es reincidente (quien pidió un crédito en el pasado desearía volver a solicitarlo en el futuro).

b) Se trata principalmente de ocupados asalariados formales o cuentapropistas informales.

c) La demanda se encuentra principalmente concentrada en los principales aglomerados urbanos del país.

d) Una alta proporción de los demandantes potenciales no están bancarizados, pero esto no necesariamente conlleva a una mayor demanda potencial de microcrédito.

e) La demanda no se correlaciona con el nivel educativo del demandante potencial.

f) La mayoría de los demandantes potenciales de microcrédito para vivienda ya son propietarios, especialmente de casas con tenencia irregular. El uso del crédito, en perspectiva, conjeturamos serviría para ampliar o mejorar una vivienda existente o construir una vivienda "social" en el mejor de los casos 4 .

g) La recepción de planes sociales o subsidios no desalienta la solicitud prospectiva de microcréditos (en particular aquellos planes o subsidios con contraprestación).

\section{Revisión de la literatura}

El conjunto de estudios referidos a los determinantes de la demanda de microcréditos o afines puede dividirse en dos grandes corrientes o macro-grupos de estudios ${ }^{5}$.

4 De hecho, así la encuesta indaga a los individuos relevados acerca de su propensión a endeudarse con fines destinados a la vivienda.

5 Dada la amplitud de la literatura precedente, un detalle metodológico de cada trabajo excedería los fines de este estudio. Por dicho motivo, nos limitaremos a una simple segregación en macro-grupos para abordar, en la siguiente sección, la literatura específica que justifica la selección de nuestras variables independientes. 
En primer lugar, están aquellos trabajos donde se estima la probabilidad de acceso efectivo a un microcrédito mediante distintas metodologías, típicamente en países en desarrollo y por lo general en hogares o poblaciones rurales (Awunyo-Vitor, 2012, para Ghana; Cheng, 2007, para China; Van Bastelaer, 2002, para Bangladesh; Díaz Quevedo, 2008, para Bolivia; Heino, 2006, para México; Balogun y Yusuf, 2011, Oriaku y Uturu, 2011 y Durojaiye et al., 2014, para Nigeria; Guérin et al., 2011, para Marruecos; Musshoff y Weber, 2013a, para Tanzania y Musshoff y Weber, 2013b para Magadascar; Samba, 2011 para Congo, entre otros).

En segundo lugar, existe otra corriente de artículos donde se busca estimar la probabilidad de repago de un microcrédito con base en distintas variables o características (Derban et al., 2005, en Reino Unido; Arene, 1992; Njoku, 1997, y Eze y Ibekwe, 2007, para Nigeria; Papias y Ganesan, 2009, en Rwanda; Reinke, 1998, en Sudafrica; Nannyonga, 2000, en Uganda; Bhatt y Tang, 2002, en los Estados Unidos; Roslan y Mohd Zaini, 2009, en Malasia; Honlonkou et al., 2006, para Benin; Sharma y Zeller, 1997 o White y Alam, 2013, para Bangladesh; entre muchos otros).

Finalmente, en línea con nuestro trabajo, una literatura más escasa y reciente buscaría estimar la probabilidad o propensión a endeudarse, o más específicamente tomar un microcrédito en un futuro (de allí el término "demanda potencial").

En este campo no encontramos investigaciones que repliquen de manera directa nuestro estudio. No obstante, existen algunos artículos más cercanos en objetivos y espíritu al presente trabajo. Por ejemplo, aquel de Denes et al. (2011) donde se realizan modelos de probabilidad condicional multivariados (Probit) para estimar los determinantes del acceso al crédito formal, informal o los determinantes del desahorro. Sin embargo, los autores se basan en una demanda pasada y no potencial o prospectiva. Sus principales conclusiones hacen referencia a las características del hogar, del principal sostén y de la situación económica que generan efectos significativos en el comportamiento financiero del hogar. A su vez, encuentran una congruencia importante con las hipótesis del ciclo de vida y del ingreso permanente.

En otra línea, Díaz Quevedo (2008) estima un modelo de tipo Logit con base en encuestas de hogares en Bolivia, la variable dependiente es una variable dummy donde la obtención de un crédito se representa con la unidad (1) y la no obtención en el pasado con cero (0). El autor busca llegar a la probabilidad de obtención de un crédito mediante el cálculo de las probabilidades marginales del modelo. Por su parte, encuentra una relación positiva 
entre dicha probabilidad y el nivel de ingreso, el género femenino -aunque recalcando la preponderancia en el enfoque de género que utiliza la tecnología microcrediticia en Bolivia podría inducir a este resultado-, el historial crediticio y la posibilidad de obtener un crédito. A su vez, resalta la importancia y su interés en la réplica del análisis en créditos para vivienda o consumo, pero no lo realiza. En esta línea, a diferencia de nuestro estudio, este artículo excluye el crédito para vivienda y se centra en la demanda pasada de los hogares informales y no en la prospectiva.

Por su parte, Nguyen (2007) analiza el mercado de crédito rural de Vietnam para comprender los determinantes en las decisiones de crédito de los hogares $\mathrm{y}$, posteriormente, medir el impacto de las actividades de endeudamiento sobre el consumo de los prestatarios. El autor recurre a la Encuesta de Hogares de Vietnam (VLSS) y, similar a Díaz Quevedo (2008), analizan la participación crediticia mediante variables binarias con base en la obtención (o no) de crédito en el pasado. En este caso se recurre a regresiones de tipo Probity Tobit. Entre los resultados a destacar se encuentra una mayor propensión a endeudarse cuando el jefe de hogar es cuentapropista, que el nivel educativo no es un factor relevante, que la edad del jefe de hogar tiene un impacto negativo, y que existe escasa evidencia sobre una mayor participación femenina con respecto al endeudamiento.

Otros autores que han abordado específicamente los determinantes en la propensión a endeudarse son Bauer, Chytilová y Morduch (2012), quienes recurren a métodos experimentales para analizar las características de comportamiento en los demandantes de microcrédito; Awunyo-Vitor, Abankwah y Kwansah (2012), quienes analizan la participación de las mujeres en cinco distritos de Ghana mediante muestreos aleatorios de etapas múltiples, o Johnston y Morduch (2007) quienes hacen lo propio con información de 1.438 hogares en seis provincias de Indonesia a través de distintos métodos.

En esta línea, si bien existen antecedentes parciales, no encontramos ningún antecedente directo a nuestro estudio. A diferencia de la literatura mencionada, en nuestro trabajo investigamos qué características socioeconómicas y demográficas en la demanda potencial de microcréditos en Argentina son diferenciales y podrían ser determinantes de la probabilidad de solicitar un microcrédito en el futuro, para finalmente poder inferir con base en dichas características si una persona tomaría o no un microcrédito en el próximo año. 


\section{Características de la demanda potencial de microcrédito en Argentina}

Los datos relevados por EDSA 2011 constan de una muestra estratificada de 5.700 hogares en 20 aglomerados urbanos de Argentina. Nuestra demanda potencial se definirá como el total de la población que posee un ingreso familiar (si es desempleado) o personal (si es empleado formal o informal) menor a dos veces el salario mínimo vital y móvil al 2011 (\$4.600 pesos argentinos) y que declaró durante el relevamiento estar interesada en demandar un crédito en los próximos 12 meses $^{6}$. Dentro de este grupo, nos encontramos con que el $47 \%$ demandaría un crédito para vivienda, el 32\% para consumo personal y el $21 \%$ para llevar adelante un emprendimiento productivo.

De este modo, con base en los resultados obtenidos y su expansión a nivel nacional, podemos encontrar un total de 2.080.187 individuos que "demandarían un crédito en los próximos 12 meses" $^{\prime 7}$. Estos individuos son, a su vez, un 10\% desempleados, un 45\% empleados informales y un $45 \%$ empleados formales.

En primer lugar, del total de demandantes potenciales de microcrédito, en la figura 1, observamos qué proporción había solicitado un préstamo en los 12 meses anteriores a ser encuestado; cuantos lo obtuvieron y cuantos no; y de haberlo obtenido, para qué fin.

Como podemos observar, existe un alto porcentaje de reincidencia en nuestra demanda potencial, ascendiendo el mismo a un $25 \%$ del total de la población. De éste, un 13\% corresponde a créditos para consumo personal, un $8 \%$ para vivienda y un $4 \%$ para un emprendimiento productivo.

Consecuentemente, podemos intuir que al existir un alto grado de reincidencia, el haber solicitado un microcrédito en el pasado incrementaría la propensión a hacerlo en el futuro. Retomaremos esta cuestión en nuestro estudio probabilístico en la sección siguiente.

6 Como dijimos anteriormente, esta definición es congruente con la propuesta por Navajas y Tejerina (2006).

7 Véase nuevamente la metodología de la EDSA 2011 aquí: http://www.uca.edu.ar/index.php/site/index/es/ uca/observatorio-de-la-deuda-social-argentina/encuesta-de-la-deuda-social/ 


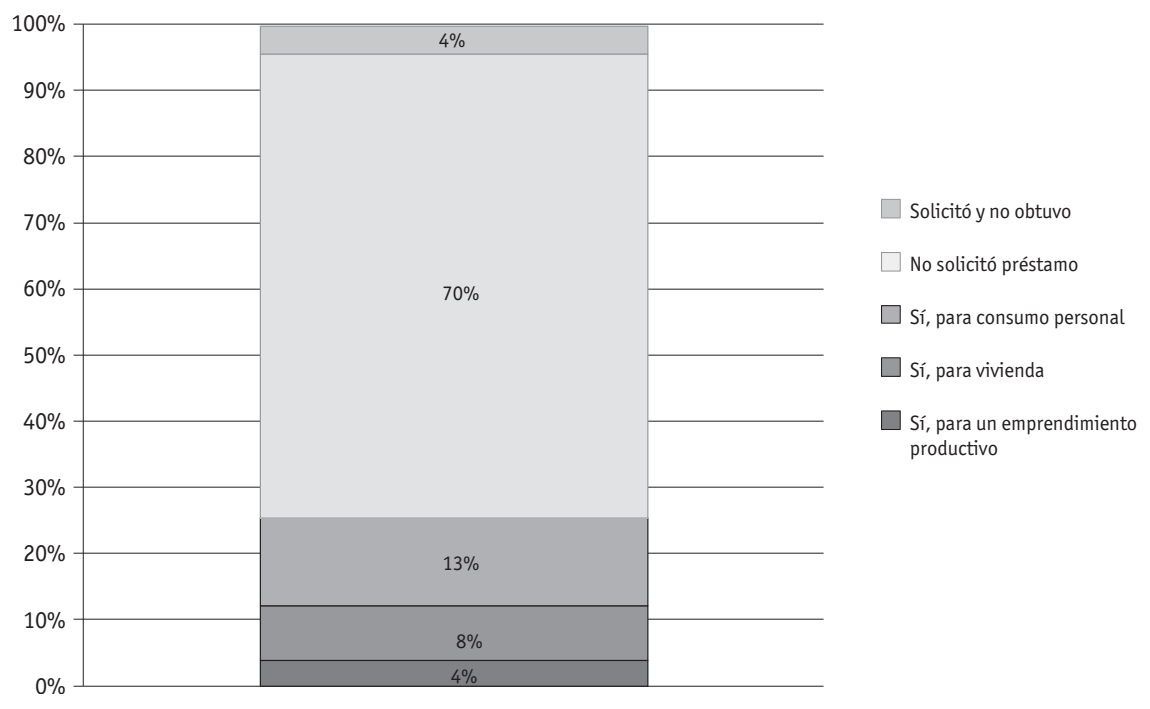

Figura 1. Demanda potencial de microcrédito que solicitó crédito en los últimos 12 meses Fuente: elaboración propia con base en datos EDSA 2011.

Al realizar el mismo análisis sobre la proporción de demandantes potenciales de crédito para vivienda, los porcentajes de reincidencia potencial serían un 15\% para vivienda, $7 \%$ para consumo y un $1 \%$ para emprendimiento productivo. En términos descriptivos, se sustenta así la tesis de que el demandante potencial de crédito para vivienda (en los estratos más bajos de ingresos de la población) se destinaría a la refacción y/o ampliación de una vivienda preexistente (ya que habría demandado por el mismo fin 12 meses antes y un $15 \%$ estaría dispuesto a demandar nuevamente). En el estudio probabilístico analizaremos este hecho.

En segundo lugar, la tabla 1 muestra las características ocupacionales de la demanda potencial. La primera mayoría corresponde a asalariados (principalmente del sector privado), seguido de empleados cuentapropistas (casi en su totalidad no profesionales). Cabe destacar el alto porcentaje de empleados domésticos y temporarios $(17,1 \%)$, generalmente asociados a la informalidad en el mercado de trabajo. Al analizar el régimen de formalidad de estas dos mayorías (figura 2), podemos afirmar que se trata, primordialmente, de asalariados formales y cuentapropistas informales. 


\section{Tabla 1}

Distribución demanda potencial de microcrédito, según ocupación

\begin{tabular}{lc}
\hline Socio patrón & $1,32 \%$ \\
\hline Asalariados del sector público & $14,59 \%$ \\
Asalariados del sector privado & $41,42 \%$ \\
\hline Total asalariados & $56,01 \%$ \\
\hline Cuentapropista profesional & $2,54 \%$ \\
Cuentapropista no profesional & 22,46 \\
\hline Total cuentapropista & $25 \%$ \\
\hline Trabajador doméstico & $9,26 \%$ \\
\hline Trabajador temporario & $7,85 \%$ \\
\hline Plan de empleo & $0,56 \%$ \\
\hline Total formales con ingreso < 4600, que demandarían crédito & $100 \%$ \\
\hline el próximo año & \\
\hline
\end{tabular}

Fuente: elaboración propia con base en datos EDSA 2011.

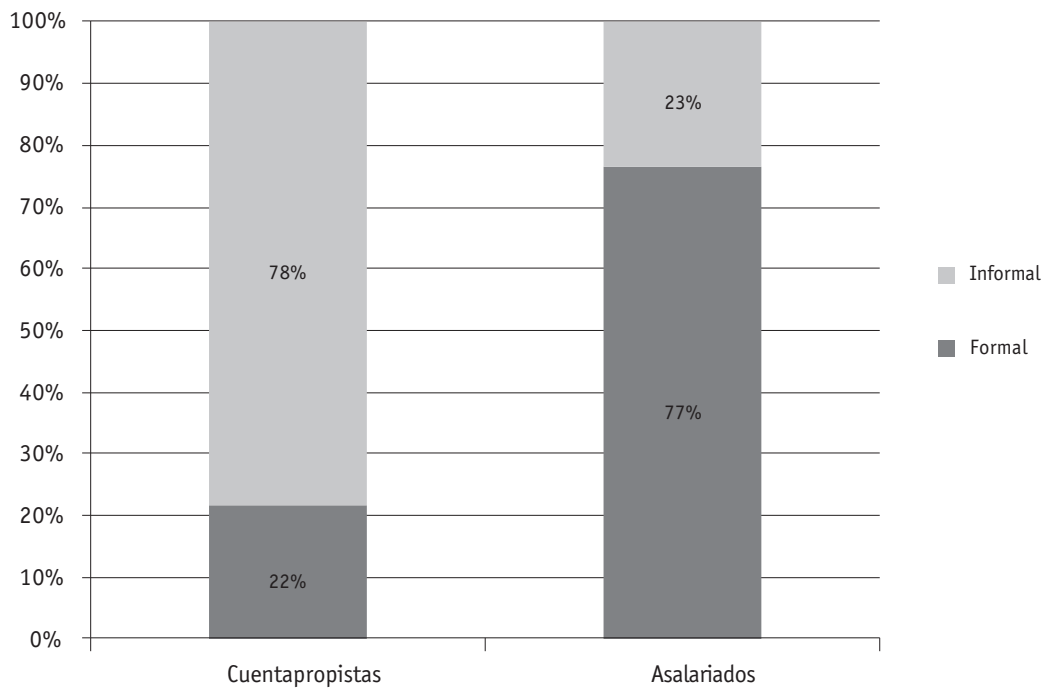

Figura 2. Demanda potencial de microcrédito asalariada y cuentapropista

Fuente: elaboración propia con base en datos EDSA 2011.

Tercero, resulta de un interés fundamental para el sistema financiero la ubicación geográfica de esos demandantes de crédito. Igual de importante es su peso relativo en el total de personas que demuestran tener una propensión favorable a endeudarse. En la figura 
3 observamos que la demanda potencial se encuentra concentrada: el $53 \%$ en Conurbano Bonaerense y la Ciudad Autónoma de Buenos Aires, y dicho porcentaje asciende a un 77\% al incluir los aglomerados de Córdoba, Rosario y Tucumán, en ese orden de importancia.

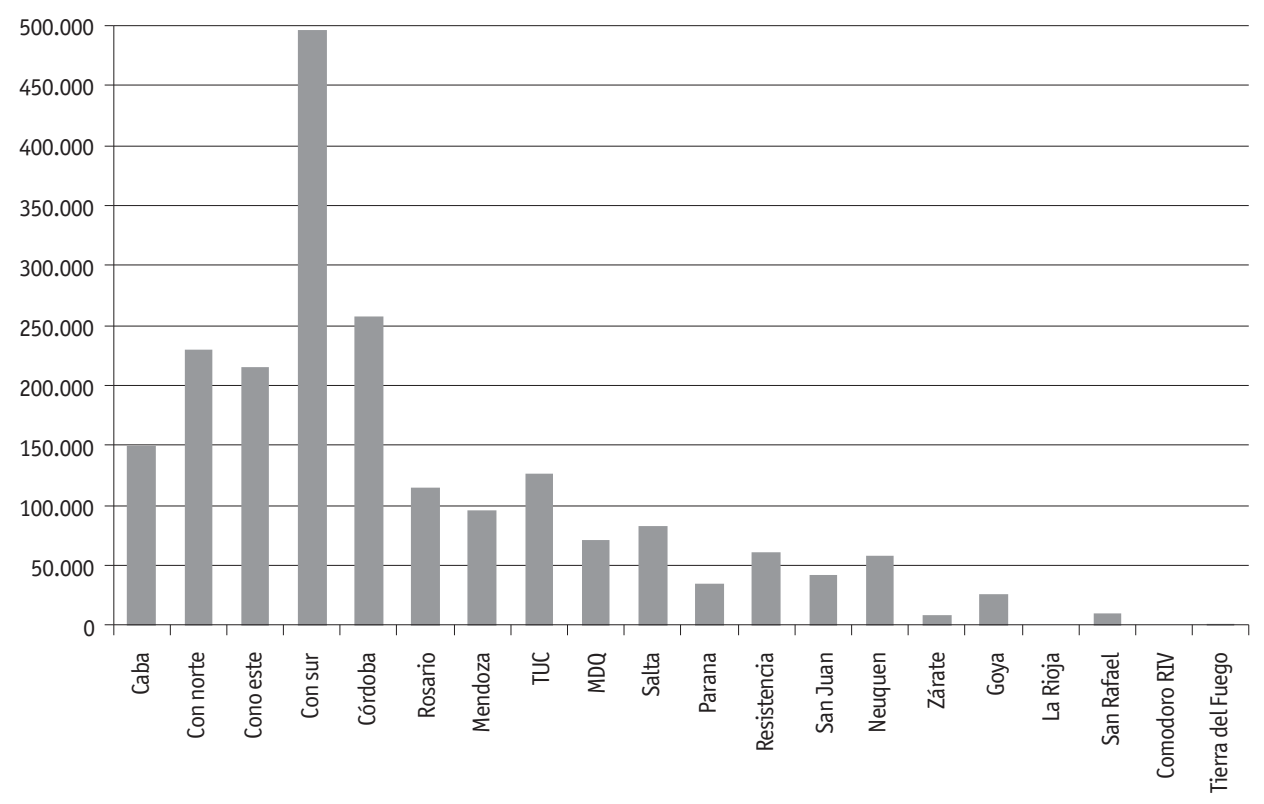

Figura 3. Distribución geográfica de la demanda de crédito para vivienda

Fuente: elaboración propia con base en datos EDSA 2011.

Por otro lado, de los 20 aglomerados de Argentina que releva el Observatorio de la Deuda Social Argentina de la Pontificia Universidad Católica Argentina, nos encontramos con que en La Rioja, Comodoro Rivadavia, y Tierra del Fuego no hay demanda potencial de microcrédito para vivienda en los estratos de menores ingresos ${ }^{8}$.

En cuarto lugar, es destacable que sólo un $27 \%$ de la demanda potencial de microcrédito posee cuenta bancaria y tarjeta de crédito. Si a esto le sumamos un $12 \%$ con cuenta bancaria únicamente, la población bancarizada que demandaría un microcrédito en los estratos de ingreso más bajos de la sociedad no supera el $40 \%$.

8 Para un análisis comparado por aglomerado EDSA 2010 y 2011 véase Anexo 1. 


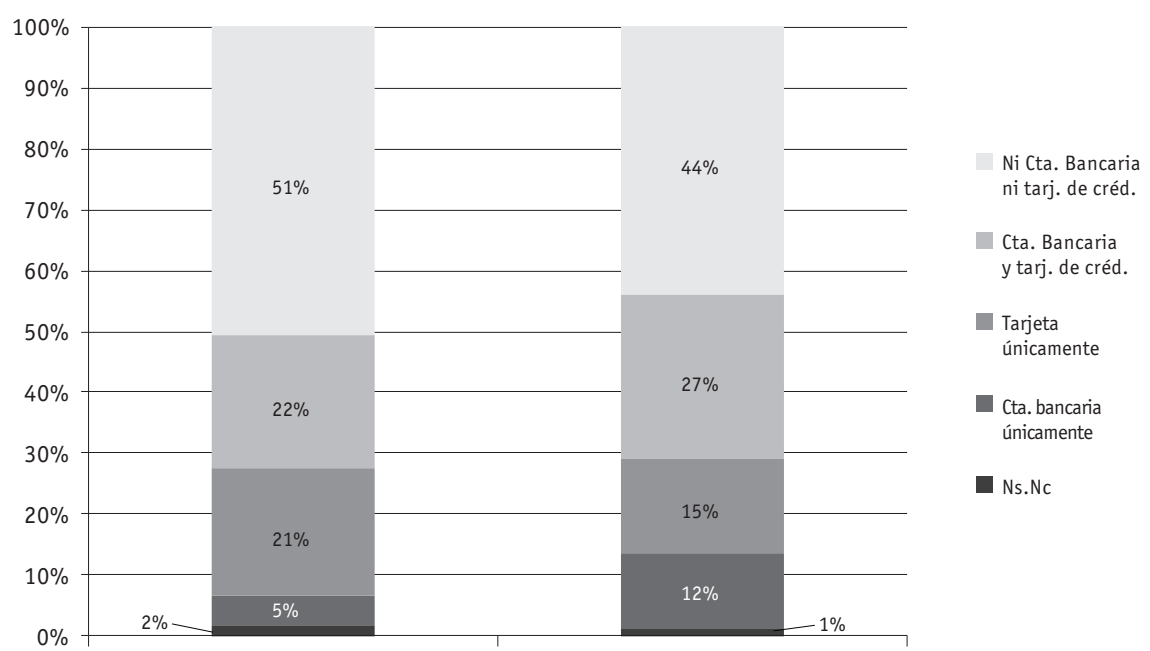

EDSA 2010

EDSA 2011

\section{Figura 4. Demanda potencial de microcrédito según bancarización}

Fuente: elaboración propia con base en datos EDSA 2011.

Como quinta característica, y en congruencia a nuestros antecedentes, encontramos que la demanda potencial de microcréditos no está correlacionada positivamente con el nivel educativo. Dado los montos de estos créditos y el hecho que la mayoría de los demandantes con ingresos menores a dos salarios mínimos no han completado el nivel de educación secundaria (47\%), no observamos diferencias apreciables en los porcentajes de demanda potencial en los distintos sub-estratos de ingreso. En otras palabras, la necesidad de microcrédito es similar independientemente del nivel educativo alcanzado por el respondiente a la EDSA como muestra la figura 5. De todos modos, en la sección siguiente retomaremos esta conclusión en nuestro análisis econométrico.

Sexto, cuando analizamos el $47 \%$ de la demanda potencial que solicitaría un microcrédito para vivienda, encontramos una alta proporción de hogares con ingresos menores a dos salarios mínimos que son propietarios (de casas generalmente en zonas alejadas o precarias y en menor proporción inquilinos, figura 6). De allíinferimos que, dados los valores de las viviendas y el suelo en Argentina, la mayor porción de la demanda potencial de crédito para vivienda en este segmento de la población sería para refacción o ampliación de la vivienda. Retomaremos este punto en la próxima sección al analizar los determinantes de probabilidad de demandar un microcrédito específicamente para vivienda. 


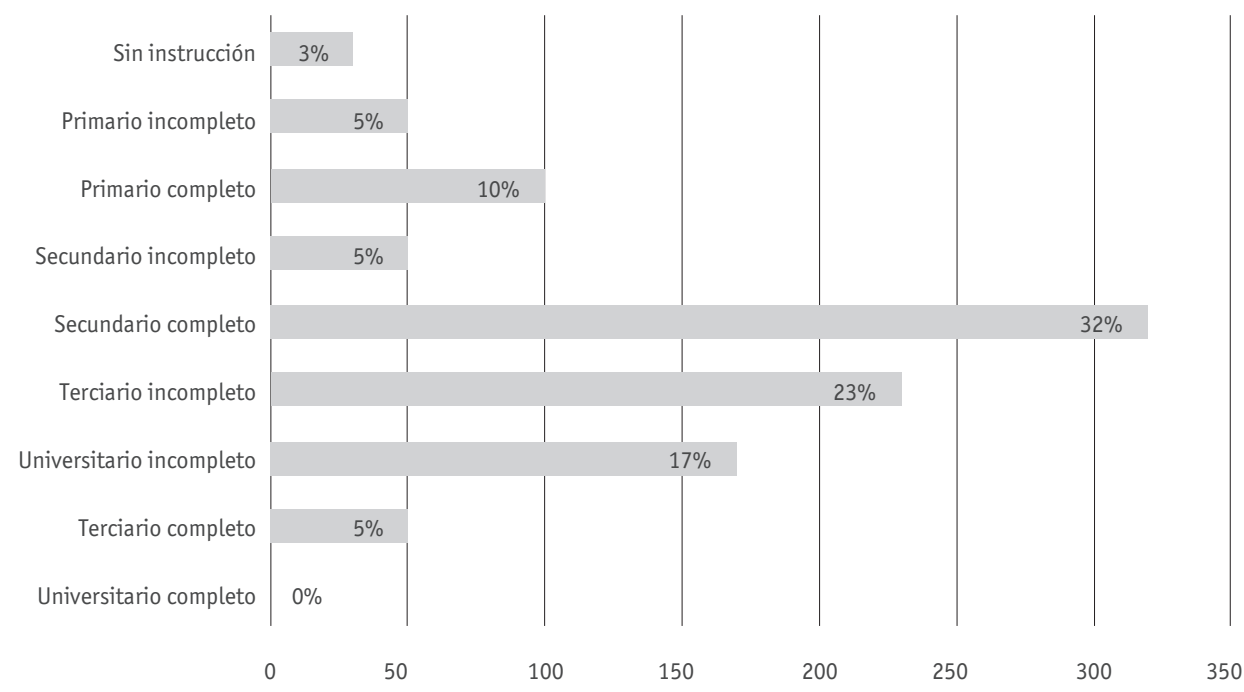

Figura 5. Demanda de crédito para vivienda según nivel educativo alcanzado

Fuente: elaboración propia con base en datos EDSA 2011.

Por último, nos interesa evaluar el porcentaje de los individuos que componen la demanda potencial de microcréditos y que posee algún plan o subsidio social bajo la forma de transferencia monetaria condicionada. La lógica detrás de este análisis es la recurrente argumentación de que la presencia de planes sociales (ayudas frente al desempleo o asignaciones por hijo) actúa como un limitante para el desarrollo de una conducta emprendedora entre los individuos ${ }^{9}$.

La figura 7 muestra que apenas el $8 \%$ de los individuos demandantes de microcrédito percibe algún plan social o transferencia condicionada. $Y$ de este $8 \%$, el $82 \%$ percibe la Asignación Universal por Hijo (AUH), una transferencia condicionada implementada en Argentina desde el año 2009. Más aún, creemos que la AUH podría ser un incentivo a tomar crédito y comenzar una actividad laboral sobre la base de un emprendimiento.

9 Al respecto de este punto debemos aclarar que la literatura económica con evidencia empírica aún es incipiente (véase Gasparini et al., 2009; Amarante et al., 2011; Garganta y Gasparini, 2012). 


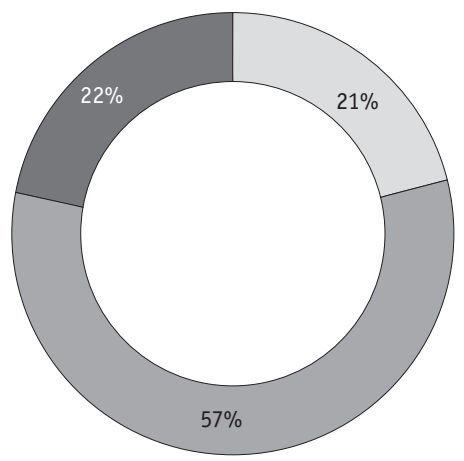

$\square$ Propietarios

$\square$ Inquilinos

$\square$ Tenencia irregular

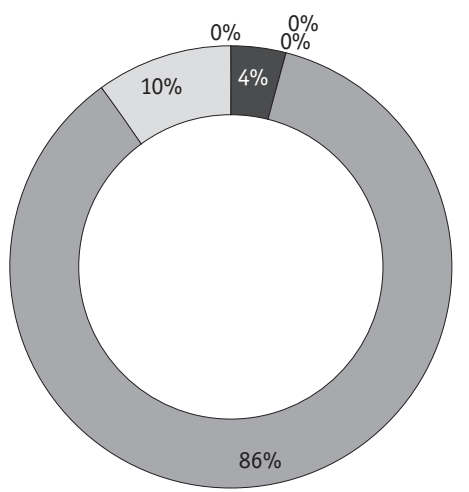

- Casa

- Departamento

$\square$ Piezas en inquilinato o conventanilla

$\square$ Casita o rancho

$\square$ Pieza en hotel

$\square 0$ treo (vivienda en lugar de trabajo, etc.)

Figura 6. Demanda de crédito según régimen de tenencia de la vivienda

Fuente: elaboración propia con base en datos EDSA 2011.

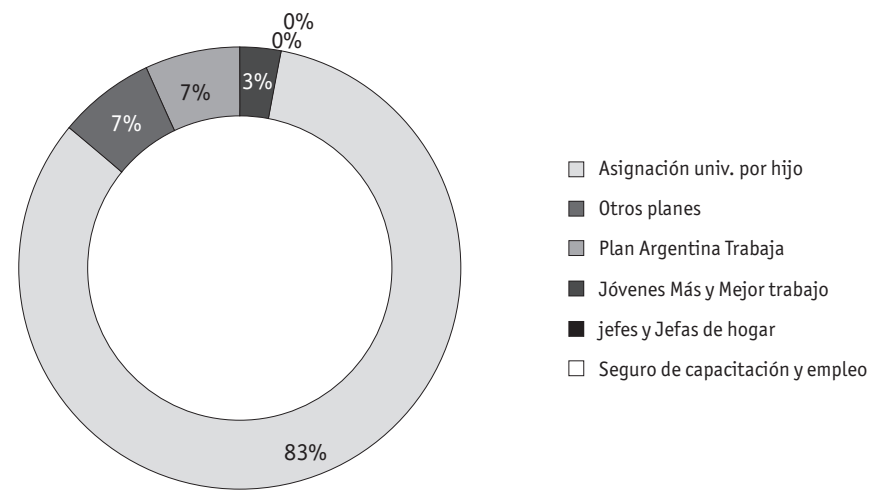

Figura 7. Distribución de la demanda potencial de microcrédito según plan social Fuente: elaboración propia con base en datos EDSA 2011. 
En esta línea también es importante analizar si entre los factores por los cuales los individuos encuestados no estarían interesados en demandar un microcrédito, se encuentra el hecho de percibir algún plan social o transferencia monetaria condicionada. Observamos que del total de individuos que respondieron no estar interesados en demandar un microcrédito en los próximos 12 meses, el subconjunto que recibe estos beneficios sociales no supera el $1 \%$, dando el indicio que no sería un desincentivo. Al igual que las otras características, incluiremos la adjudicación transferencias condicionadas en nuestro estudio econométrico a realizar en la siguiente sección.

\section{Probabilidad condicional que un hogar tome un crédito}

Una vez caracterizada la demanda potencial de microcréditos en Argentina, es decir, definidas y descriptas sus principales variables condicionantes, nos interesa conocer cuál es la probabilidad que un individuo perteneciente al estrato de menores ingresos (menor a dos salarios mínimos de Argentina en 2011) y sujeto de microcrédito, declare estar interesado en demandar un microcrédito para producción o vivienda. En nuestro análisis hemos excluido los microcréditos para consumo porque, si bien representan un porcentaje significativo de la muestra en términos prospectivos, no se considera que contribuyan a mejorar la productividad e ingresos del encuestado ni tampoco las condiciones habitacionales en la misma medida que un crédito productivo o para vivienda.

En esta sección planteamos un modelo de variables binarias donde estimamos cuál es la probabilidad de que un individuo encuestado y definido como sujeto de microcrédito manifieste la intención de tomar un crédito en los próximos 12 meses. Particularmente, analizaremos dicha probabilidad condicionada a las características de la persona, el hogar y su entorno sociodemográfico según analizamos en la sección precedente.

En los modelos de variables binarias, la variable dependiente sólo puede asumir dos valores posibles. Si representamos con $p$ a la probabilidad de que la variable dependiente tome uno de los valores, entonces la probabilidad de que tome el otro valor es $(1-p)$. La probabilidad $p$ varía entre los individuos en función de las variables independientes. Los modelos Logit y Probit son los dos modelos comunes que existen para las variables binarias y difieren en la forma funcional que especifican para esta probabilidad. En estos modelos la estimación se realiza por máxima verosimilitud porque la distribución de los datos está definida por el modelo de Bernoulli (Cameron y Trivedi, 2005). 
De esta manera, la probabilidad $p$ depende de un vector $X$ de variables regresoras y un vector de parámetros $\beta$ como se explica más adelante.

Proponemos un modelo de variables binarias ya que, como sabemos, para estimar la probabilidad de un evento, el modelo lineal tiene como desventaja que la estimación puede ser menor que cero o mayor a uno, y que el efecto parcial de cualquier variación explicativa es constante. Así, para nuestra muestra adoptamos un modelo de probabilidad de respuesta con función logística (Logit) ponderando igualmente cada variable para un total de 2.537 observaciones que corresponden a aquellos hogares que satisfacen los criterios limitantes de la demanda potencial de microcréditos como se expuso en la sección precedente ${ }^{10}$.

\subsection{Especificación del modelo}

$$
P(y=1 / X)=G(X \beta) \equiv G(z)
$$

Donde $Y=1$ implica que el individuo responde afirmativamente querer tomar un microcrédito ya sea para vivienda o emprendimiento productivo en los próximos 12 meses, e $Y=0$ lo contrario. A su vez, $X$ es el vector de variables condicionantes o explicativas del modelo y $0<G(z)<1$ para todos los números reales $z$, y creciente en $z$.

$$
G(z)=\Phi(z)=\int_{-\infty}^{z} \phi(v) d v
$$

Donde $\phi(v)$ es la densidad normal estándar $\varphi(v)=(2 \pi)^{-1 / 2} \exp \left(-z^{2} / 2\right)$

En los modelos Logit, $\mathrm{G}(\cdot)$ es una función de distribución acumulativa de la distribución logística. La ecuación que representa el modelo Logit se puede escribir del siguiente modo.

$$
G(z)=\exp (z) /[1+\exp (z)]
$$

Una vez estimado el modelo, según (1) a (3), puede evaluarse el efecto parcial o marginal de la variable $x_{i}$ sobre $P$ evaluado en algún valor del vector $X$, como por ejemplo la media. Para ello es necesario hallar la derivada parcial de $\mathrm{P}($.$) respecto a x_{i}$ :

10 Debido a una cuestión de espacio así como a una sugerencia de uno de los evaluadores anónimos -que señaló la mejor performance relativa de los modelos Logit en especificaciones como la nuestra- es que no se incluyen las regresiones Probit. Sin embargo, estas arrojan resultados similares a las regresiones Logit y se encuentran disponibles a pedido del lector. 
4)

$$
\frac{\partial p(\boldsymbol{X})}{\partial x_{i}}=g(X \beta) \beta_{i} \text { donde } g(z) \equiv \frac{\partial G(z)}{\partial z}
$$

Es importante notar que como $G$ es creciente en $z$, la derivada parcial $g(X \beta)$ siempre tiene el mismo signo que $\beta$.

Asimismo, si $X_{i}$ es una variable binaria, el efecto parcial de cambiar $X_{i}$ de cero a uno (o bien de cero a la media) es simplemente $G\left(\beta_{0}+\beta_{1} X_{1}+\ldots+\beta_{i} X_{i}\right)-G\left(\beta_{0}+\beta_{1} X_{1}+\ldots+\beta_{i-1} X_{i-1}\right)$.

\subsection{Variables e impactos esperados}

Como ya se explicó, aunque con metodologías o abordajes distintos a nuestro estudio, la literatura precedente ha analizado en profundidad un conjunto de características influyentes en la demanda de microcréditos o en su capacidad de repago. Las variables mayormente tratadas son: el ingreso o poder adquisitivo (Nannyonga, 2000), el estado ocupacional (Arene, 1992), el género (Papias y Ganesan, 2009; Khander et al., 1995; Derban et al., 2005; Sharma y Zeller, 1997), la edad (Eze y Ibekwe, 2007; Papias y Ganesan, 2009; Aguilera y Gonzalez-Vega; 1998; Reinke, 1998; Nannyonga, 2000) y el nivel educativo (Bhatt y Tang, 2002; Arene, 1992; Nikhade et al., 1994; Eze y Ibekwe; 2007; Rambabu y Eswaran 1994).

En nuestro trabajo, analizamos la condicionalidad generada por estas características en la propensión a endeudarse. Pero también, incorporamos otras dimensiones facilitadas por la EDSA y que resultaron relevantes en el análisis descriptivo de la sección anterior. En este sentido, analizamos también la reincidencia de la demanda potencial, el nivel de bancarización, el régimen de propiedad de la vivienda, el estatus marital, el aglomerado de residencia y la recepción de planes o subsidios sociales.

Consecuentemente, los principales impactos marginales teóricos y esperados de las variables $x_{i}$ evaluados en su media serán los siguientes:

- Reincidencia de la demanda de microcrédito. Se espera un impacto positivo. En quien pidió un crédito en el pasado, mayor será la probabilidad de volver a solicitarlo en el futuro, independientemente del destino.

- Ocupación o tipo de empleo. Se espera un impacto positivo en concordancia con la mayor parte de la literatura. Esto es, en quien se encuentra empleado, mayor 
será la probabilidad solicitar un microcrédito en el futuro. En términos de informalidad laboral, cuanto mayor sea la estabilidad laboral de los ocupados, mayor será la probabilidad de demanda de crédito. Se intuye aún mayor en microcréditos productivos y menor en microcréditos para vivienda.

- Género. Se espera un impacto positivo en el género femenino en concordancia con la mayor parte de la literatura.

- Estado civil casado. Se espera un impacto positivo, especialmente en créditos para vivienda. Quien se encuentra casado y en concubinato, tendrá mayores incentivos a demandas habitacionales.

- Residencia en los principales aglomerados urbanos de Argentina. Se espera un impacto positivo, ya que tienen una mayor propensión marginal histórica a demandar microcréditos con base enl mayor acceso y oferta disponible.

- Edad. Se espera un impacto positivo en concordancia con la mayor parte de la literatura precedente (ídem con su variable exponencial elevada al cuadrado).

- Bancarización (tiene tarjeta y cuenta bancaria). Se espera un impacto negativo. Esto obedecería a que la inclusión financiera formal actuaría como un sustituto de los microcréditos en general, y en particular aquellos no otorgados por entidades bancarias.

- Nivel educativo inferior a secundario completo. Se espera un impacto neutro o no significativo en concordancia con la literatura precedente.

- Plan o subsidio social con contraprestación. Se espera un impacto positivo. Los planes con contraprestación proveen un horizonte de estabilidad de ingresos a los beneficiarios y, esperamos, deberían incentivar otras actividades emprendedoras o la incursión en el mercado de crédito.

Por lo tanto, las regresiones estiman la probabilidad de tomar un microcrédito productivo o para vivienda durante el año siguiente al de la encuesta. Diferenciamos según si el lugar de residencia es en un gran aglomerado o ciudad (Ciudad de Buenos Aires, Gran Buenos Aires, Córdoba o Rosario), según su edad, sexo, estado civil, nivel educativo (si tiene secundaria completa), situación ocupacional (cuentapropista, profesional independiente, empleado público, empleado privado, si el encuestado cuenta con un empleo precario o tiene un plan social con contraprestación), situación laboral (informal, desocupado y como variable base formal), el status respecto a la vivienda (propietario, inquilino), si está bancarizado (tarjeta habiente y una cuenta bancaria) y si recibe algún plan o beneficio social (con contraprestación). Todas las variables independientes son binarias con excepción de la edad. 


\subsection{Estimación de máxima verosimilitud}

Dada la naturaleza no lineal de los modelos de probabilidad de respuesta, estimamos los coeficientes de la ecuación (1) por máxima verosimilitud, es decir que encontramos los valores de los $\beta$ que maximizan la función de máxima verosimilitud como sigue.

$$
\begin{gathered}
\operatorname{Max} L(\beta)=\sum_{i=1}^{n} l_{i}(\beta) \\
\text { donde } l_{i}(\beta)=y_{i} \log \left[G\left(X_{i} \beta\right)\right\rfloor+\left(1-y_{i}\right) \log \left\lfloor 1-G\left(X_{i} \beta\right)\right\rfloor
\end{gathered}
$$

La tabla 2 muestra las estadísticas descriptivas de las distintas variables.

\section{Tabla 2}

\begin{tabular}{|c|c|c|c|c|c|}
\hline & Variables & Media & SD & Min & $\operatorname{Max}$ \\
\hline \multirow{5}{*}{ ¿Solicitó préstamo? } & Si, solicitó y lo obtuvo & $13,6 \%$ & $34,3 \%$ & 0 & 1 \\
\hline & Productivo & $1,7 \%$ & $12,9 \%$ & 0 & 1 \\
\hline & Vivienda & $4,3 \%$ & $20,3 \%$ & 0 & 1 \\
\hline & Consumo & $7,6 \%$ & $26,6 \%$ & 0 & 1 \\
\hline & Si, solicitó y no obtuvo & $4,9 \%$ & $21,5 \%$ & 0 & 1 \\
\hline \multirow{4}{*}{$\begin{array}{l}\text { ¿Solicitaría } \\
\text { préstamo? }\end{array}$} & Si, lo solicitaría & $23,6 \%$ & $42,5 \%$ & 0 & 1 \\
\hline & Productivo & $5,1 \%$ & $21,9 \%$ & 0 & 1 \\
\hline & Vivienda & $11,0 \%$ & $31,3 \%$ & 0 & 1 \\
\hline & Consumo & $7,6 \%$ & $26,5 \%$ & 0 & 1 \\
\hline Ciudad & Grandes (BA, GBA, CBA, ROS) & $73,3 \%$ & $44,2 \%$ & 0 & 1 \\
\hline Sexo & Femenino & $45,2 \%$ & $49,8 \%$ & 0 & 1 \\
\hline Edad & Años & 38,51 & 13,88 & 18 & 88 \\
\hline Estado civil & En pareja & $51,5 \%$ & $50,0 \%$ & 0 & 1 \\
\hline Educación & Secundaria completa & $54,4 \%$ & $49,8 \%$ & 0 & 1 \\
\hline \multirow{6}{*}{ Ocupación } & Cuentapropista & $26,8 \%$ & $44,3 \%$ & 0 & 1 \\
\hline & Profesional & $3,1 \%$ & $17,3 \%$ & 0 & 1 \\
\hline & Empleo público & $10,7 \%$ & $31,0 \%$ & 0 & 1 \\
\hline & Empleo privado & $35,0 \%$ & $47,7 \%$ & 0 & 1 \\
\hline & Empleo precario & $15,3 \%$ & $36,0 \%$ & 0 & 1 \\
\hline & Plan social con contraprestación & $0,8 \%$ & $9,0 \%$ & 0 & 1 \\
\hline
\end{tabular}

Características de los demandantes potenciales de microcrédito- 2011 


\begin{tabular}{|c|c|c|c|c|c|}
\hline & Variables & Media & SD & Min & Max \\
\hline \multirow{2}{*}{ Vivienda } & Propietario & $66,0 \%$ & $47,4 \%$ & 0 & 1 \\
\hline & Inquilino & $19,7 \%$ & $39,8 \%$ & 0 & 1 \\
\hline \multirow{3}{*}{ Situación laboral } & Formal & $43,2 \%$ & $49,5 \%$ & 0 & 1 \\
\hline & Informal & $48,3 \%$ & $50,0 \%$ & 0 & 1 \\
\hline & Desocupado & $8,5 \%$ & $27,9 \%$ & 0 & 1 \\
\hline Bancarizado & Tiene tarjeta y cuenta bancaria & $24,0 \%$ & $42,7 \%$ & 0 & 1 \\
\hline Plan social & Recibe plan social & $9,1 \%$ & $28,8 \%$ & 0 & 1 \\
\hline
\end{tabular}

Fuente: elaboración propia con base en datos EDSA 2011.

Las tablas A.2.1 y A.2.2 en el Anexo 2 muestran los resultados de la regresión Logit para las probabilidades de demanda de microcréditos para fines productivos y vivienda. Previamente al análisis de la significatividad individual de las variables regresoras y el impacto marginal de estas (evaluadas en la media) en la variable dependiente, es oportuno analizar la capacidad explicativa global del modelo Logit.

En Stata v.13 existen una serie de criterios para cuantificar cuán bien predicen globalmente las variables $X$ la probabilidad que un encuestado desee tomar un microcrédito productivo o de vivienda. Esos criterios son a) el porcentaje predicho correctamente por la función Logit estimada, b) el test de significatividad global de Wald (Chi-cuadrado) y c) el coeficiente Pseudo $\mathrm{R}^{2}$. En nuestro caso, sólo nos guiaremos por el test de Wald además de la significatividad individual de las variables explicativas reportadas en las tablas A.2.1 y A.2.2.

Según Wooldridge (2006) la bondad del ajuste es usualmente menos importante que obtener estimaciones convincentes del efecto ceteris paribus de las variables explicativas, es decir, los efectos marginales que reproducimos más abajo. Más aún, los indicadores Pseudo $\mathrm{R}^{2}$ y los porcentajes predichos correctamente deben ser interpretados con mucha cautela o descartados ya que son muy sensibles a criterios pre-establecidos en relación al valor de corte de la función de acumulación $\mathrm{G}$ (.) o a los estimadores de máxima verosimilitud, respectivamente ${ }^{11}$.

11 De hecho podría ocurrir como en nuestras regresiones que los porcentajes predichos sean altos ( $95 \%$ y $89 \%$ en cada regresión de microcréditos productivos y de vivienda respectivamente) y sin embargo los Pseudo $\mathrm{R}^{2}$ arrojen valores "bajos" (6\%). 
Respecto a los efectos de las variables explicativas, los resultados más destacados de nuestro estudio econométrico son los siguientes:

- El hecho que el encuestado haya solicitado un préstamo el año anterior y lo haya obtenido, parecería tener un impacto positivo aunque reducido en la probabilidad de solicitar un micropréstamo para vivienda; no así en el caso de microcréditos con fines productivos.

- La ocupación tanto en el sentido si la persona está ocupada como el tipo de ocupación es la variable más relevante para la decisión de tomar un microcrédito el próximo año, excepto por la categoría de profesional independiente. Sin embargo, la desocupación no está correlacionada positiva y significativamente con la probabilidad de tomar un microcrédito en los próximos 12 meses.

- La informalidad no es significativa en ninguna de las dos ecuaciones. Es probable que dentro de las variables ocupacionales, la variable cuentapropista ya esté capturando el efecto de la informalidad sobre la probabilidad de solicitar un microcrédito para ambos fines.

- Se observa una mayor propensión a tomar crédito en las personas de mayor edad a una tasa decreciente en consonancia con nuestra hipótesis. Sin embargo, contrario a la creencia más general, el mismo se orienta especialmente en los microcréditos para vivienda.

- Que un individuo posea al menos el nivel de educación "secundario completo", no tiene un impacto positivo ni significativo en la propensión a solicitar un microcrédito. Validando la hipótesis de que la educación no explica la probabilidad de la demanda prospectiva de microcrédito.

- Contrariamente a lo esperado, y postulado por nuestra hipótesis, la bancarización no tiene un impacto diferencial en la probabilidad de tomar un microcrédito productivo o para vivienda.

- La conclusión es similar para el tipo de ciudad donde vive el solicitante, no validando así nuestra hipótesis que postulaba que dicha probabilidad crecería si el lugar de residencia fuese alguno de los principales cuatro aglomerados.

- Las mujeres tienen una menor propensión que los hombres a solicitar un microcrédito con fines productivos. contrario a la hipótesis planteada más arriba. No se observa ningún efecto diferencial en el caso de la demanda de microcrédito para vivienda.

La tabla 3 resume los efectos marginales según la ecuación (4) evaluando las variables independientes en la media. 


\section{Tabla 3}

Efectos marginales en las regresiones Logit demandar un microcrédito en 2011

\begin{tabular}{|c|c|c|c|}
\hline & Modelo Logit - $\mathrm{dF} / \mathrm{dx}$ & Productivo & Vivienda \\
\hline \multirow{2}{*}{ Préstamo } & Si, solicitó y lo obtuvo & $1,39 \%$ & $5,6 \%$ \\
\hline & Si, solicitó y no obtuvo & $3,0 \%$ & $-1,8 \%$ \\
\hline Ciudad & Grandes (BA, GBA, CBA, ROS) & $-0,3 \%$ & $-0,4 \%$ \\
\hline Sexo & Femenino & $-1,7 \%$ & $1,3 \%$ \\
\hline \multirow{2}{*}{ Edad } & Años & $0,3 \%$ & $0,6 \%$ \\
\hline & Años al cuadrado & $0,0 \%$ & $0,0 \%$ \\
\hline Estado civil & En pareja & $-0,6 \%$ & $2,8 \%$ \\
\hline Educación & Secundaria completa & $-0,3 \%$ & $0,5 \%$ \\
\hline \multirow{6}{*}{ Ocupación } & Cuentapropista & $16,6 \%$ & $38,2 \%$ \\
\hline & Profesional & $4,3 \%$ & $-3,8 \%$ \\
\hline & Empleo público & $49,8 \%$ & $45,1 \%$ \\
\hline & Empleo privado & $31,5 \%$ & $36,0 \%$ \\
\hline & Empleo precario & $39,8 \%$ & $46,5 \%$ \\
\hline & Plan social con contraprestación & n.a. & $19,5 \%$ \\
\hline Vivienda & Propietario & $1,4 \%$ & $-0,7 \%$ \\
\hline \multirow{2}{*}{ Situación laboral } & Informal & $1,5 \%$ & $1,7 \%$ \\
\hline & Desocupado & $1,1 \%$ & $2,8 \%$ \\
\hline Bancarizado & Tiene tarjeta y cuenta bancaria & $0,5 \%$ & $0,6 \%$ \\
\hline Plan social & Recibe plan social & $-0,2 \%$ & $-1,6 \%$ \\
\hline
\end{tabular}

Fuente: elaboración propia con base en datos EDSA 2011.

\section{Conclusiones}

En el presente trabajo estudiamos la demanda potencial de microcréditos de los sectores de menores ingresos en Argentina durante el periodo 2011 recurriendo a la Encuesta de la Deuda Social Argentina de la Pontificia Universidad Católica Argentina.

A través de un análisis descriptivo y una posterior estimación econométrica binaria de tipo Logit, obtuvimos resultados que nos permitieron esclarecer nuestras hipótesis iniciales. De manera general, encontramos que el principal factor explicativo de la probabilidad de solicitar un microcrédito al año subsiguiente a ser encuestado es la ocupación (tanto en el sentido de si la persona está ocupada, como el tipo de ocupación, excepto profesional independiente), especialmente en aquellos con empleo precario. Asimismo, si bien la 
informalidad no resulta significativa, lo es indirectamente a través de la categoría de ocupados cuentapropistas. Este hecho es consistente con la evidencia empírica en Argentina y otros países de América Latina.

Por otro lado, dado los montos habituales de estos préstamos, y el hecho de que la mayoría de los demandantes con ingresos menores a dos salarios mínimos en Argentina tengan un bajo nivel educativo, nuestros resultados nos permiten concluir que la propensión a solicitar un microcrédito es independiente del nivel educativo alcanzado por el respondiente de la encuesta. A su vez, la edad guarda una relación positiva con la probabilidad de solicitar un microcrédito aunque de modo decreciente cuando avanza el ciclo de vida. Al mismo tiempo, observamos que el fin del microcrédito es fundamental para entender la demanda. Las características del individuo pueden tener un impacto positivo, negativo, o no tenerlo, según cual sea el destino del microcrédito declarado por el encuestado.

En este sentido, las mujeres tienen una propensión marginal menor a solicitar microcréditos productivos, contrario a la intuición o creencia popular de la "mujer micro-emprendedora social". Esto cuestiona el paradigma tradicional observado en otros países y amerita una línea de investigación futura para responder a la mayor tasa relativa de participación de los hombres en el mercado de microcréditos, o como mínimo su mayor propensión a endeudarse.

Finalmente, el hecho de que la persona haya solicitado y obtenido un préstamo el año anterior tiene relación con la propensión a solicitar un préstamo el año siguiente. Sin embargo, dicho resultado es congruente con el patrón de demanda de crédito para vivienda, y no con aquel de demanda para fines productivos.

En este sentido, un corolario final de este trabajo atiende a que las políticas de incentivo 0 acceso al microcrédito, deben estar indefectiblemente diferenciadas según el fin que tenga el préstamo. Particularmente para Argentina, y con base en los resultados de esta investigación, deberán contemplar el apetito local por refaccionar, ampliar o terminar una vivienda con el fin de mejorar las condiciones de vida y habitacionales en consecuencia. Sin embargo, para futuras investigaciones se podría replicar este estudio para distintos años o periodos del tiempo con el objeto de brindar robustez a nuestros resultados. 


\section{Referencias}

Amarante, V.; M. Manacorda, A. Vigorito, and M.Zerpa. (2011). Social assistance and labor market outcomes: Evidence from the Uruguayan PANES. Washington: AIDB.

Anyiro, C.0.; and B.N. Oriaku. (2011). Access to and investment of formal micro credit by small holder farmers in Abia State, Nigeria. A case study of Absu Micro Finance Bank, Uturu. Journal of Agricultural Sciences, 6 (2).

Arene, C.J. (1992). Loan repayment and technical assistance among small-holder maize farmers in Nigeria. African Review of Money Finance and Banking, 63-74.

Armendáriz, B.; and J. Morduch. (2010). The economics of microfinance. MIT Press.

Awunyo-Vitor, D.; V. Abankwah, and J. Kwansah. (2012). Women participation in microcredit and its impact on income: A study of small-scale businesses in the central region of Ghana. American Journal of Experimental Agriculture, 2 (3), 502.

Balogun, 0.L.; and S.A. Yusuf. (2011). Determinants of demand for microcredit among the rural households in South-Western States, Nigeria. Journal of Agriculture and Social Sciences. Pakistan.

Bauer, M.; J. Chytilová, and J. Morduch. (2012). Behavioral foundations of microcredit: Experimental and survey evidence from rural India. The American Economic Review, 102 (2), 1118-1139.

Bebczuk, R. N.; and F. Haimovich. (2007). MDGs and microcredit: An empirical evaluation for Latin American Countries. Documentos de Trabajo del CEDLAS.

Bhatt, N.; and S.Y. Tang. (2002). Determinants of repayment in microcredit: Evidence from programs in the United States. International Journal of Urban and Regional Research, 26 (2), 360-376.

Cameron, A.C.; and P.K. Trivedi. (2005).Microeconometrics: Methods and applications. Cambridge University Press.

Carballo, I.; F. González Rouco y M. Grandes. (2015). Evaluando la creación de empleo del Plan Pro.Cre.Ar con información incompleta. VI Congreso Anual. El futuro del desarrollo argentino. Buenos Aires: AEDA.

CGAP - Consultative Group to Assist the Poor. (2009). About microfinance. Recuperado de www. cgap.org

Cheng, E. (2007). The demand for microcredit as a determinant for microfinance outreach-evidence from China. Savings and Development, 31, 307-334.

Crouzel, R. (2009). ¿Por qué las microfinanzas no se desarrollan con más éxito en Argentina. IDLO Microfinance Research Paper. May.

Cull, R.; T. Ehrbeck y N. Holle. (2014). La inclusión financiera y el desarrollo: pruebas recientes de su impacto. Enfoques, 92, Washington: CGAP. 
Curat, P.; J. Lupano y I. Adúriz. (2006). Demanda potencial por microcréditos en el Conurbano Bonaerense. Fundación Andares.

Denes, A.; C. Maya, G. Repetto y N. Grosman. (2011). El uso simultáneo de crédito formal, informal y el desahorro: explorando el comportamiento financiero de los hogares en Argentina. Documentos de Trabajo, 51.

Derban, W.K.; J.M. Binner, and A. Mullineux. (2005). Loan repayment performance in community development finance institutions in the UK. Small Business Economics, 25 (4), 319-332.

Díaz Quevedo, 0. (2008). Determinantes del acceso al microcrédito para emprendedores bolivianos. Banco Central de Bolivia.

Duflo, E.; A. Banerjee, R. Glennerster, and C. Kinnan. (2013). The miracle of microfinance? Evidence from a randomized evaluation No. w18950. National Bureau of Economic Research.

Durojaiye, A.M.; S.A. Yusuf, and 0.L. Balogun. (2014). Determinants of demand for microcredit among grain traders in Southwestern States, Nigeria.

Eze, C.C.; and U.C. Ibekwe. (2007). Determinants of loan repayment under the indigenous financial system in Southeast, Nigeria. The social sciences, 2 (2), 116-120.

Foltz, J.D. (2004). Credit market access and profitability in Tunisian agriculture. Agricultural Economics, 30 (3), 229-240.

Garganta, S.; y L. Gasparini. (2012). El impacto de un programa social sobre la informalidad laboral: el caso de la AUH en Argentina. Documento de trabajo, 133.

Gasparini, L.; F. Haimovich, and S. Olivieri. (2009). Labor informality bias of a poverty-alleviation program in Argentina. Journal of Applied Economics, 12 (2), 181-205.

Grandes, M. (2014). Microfinanzas en la Argentina. Buenos Aires: Grupo Editorial Temas.

Grandes, M.; A. Martiarena, and F. Fariña. (2010). ¿Y dónde está la demanda? Una nueva metodología para cuantificar y caracterizar la demanda potencial por microcréditos en Argentina. Documento de Trabajo de la Escuela de Negocios de la UCA, 5.

Guérin, I.; S. Morvant-Roux, M. Roesch, J. Moisseron, and P. Ould-Ahmed. (2011). Analysis of the determinants of the demand for financial services in rural Morocco. Impact Analyses Series, 6.

Guirkinger, C.; D. Fletschner, and S. Boucher. (2007, July). Credit constraints and financial efficiency in Peruvian agriculture. In American Agricultural Economics Association Annual Meeting.

Heino, H. (2006). Use of borrowed start-up capital and micro enterprises in Mexico: Existence of liquidity constraints. Portuguese Economic Journal, 5 (1), 1-30.

Helms, B. (2006). Access for all: Building inclusive financial systems. Washington: CGAP.

Honlonkou, A.N.; D.H. Acclassato, et C.V. Quenum. (2006). Déterminants de la performance de remboursement dans les institutions de microfinance au Bénin. Annals of Public and Cooperative Economics, 77 (1), 53-81. 
Impulso Argentino. (2014). Microcréditos en Argentina: estimación de su demanda potencial y análisis del perfil de sus destinatarios. Buenos Aires: Foncap.

Johnston, D., and J. Morduch. (2007). Microcredit vs. microsaving: Evidence from Indonesia. In Conference on Financial Access, Washington DC.

Khandker, S.R.; M.B. Khalily, and Z.H. Khan. (1995). Grameen Bank: Performance and sustainability, vol. 306. Washington: World Bank Publications.

Morduch, J. (1998). Does microfinance really help the poor? New evidence from flagship programs in Bangladesh. Research Program in Development Studies, Woodrow School of Public and International Affairs.

Musshoff, R., and 0. Weber. (2013a). Is agricultural microcredit really more risky? Evidence from Tanzania. Agricultural Finance Review, 72 (3), 416-435.

Musshoff, R., and 0. Weber. (2013b). Can flexible microfinance loans improve credit access for farmers? Agricultural finance review, 73 (2), 255-271.

Nannyonga, H. L. (2000). Determinants of repayment behavior in the Centenary Rural Development Bank in Uganda. Doctoral dissertation, The Ohio State University.

Navajas, S., and L. Tejerina. (2006). Microfinance in Latin America and the Caribbean: Connecting Supply and Demand. Washington: IADB.

Nguyen, C.H. (2007). Determinants of credit participation and its impact on household consumption: Evidence from rural Vietnam.

Nikhade, D.M.; P.S. Shinde, and S.M. Nighot. (1994). Crop loan repayment behaviour in cotton growers. Agricultural Banker, 13-16.

Njoku, J.E.; and M.A. Odii. (1991). Determinants of Loan Repayment under the Special Emergency Loan Scheme in Nigeria: A case study of Imo State. African Review of Money Finance and Banking, 39-52.

Papias, M., and P. Ganesan. (2009). Repayment behaviour in credit and savings cooperative societies: Empirical and theoretical evidence from rural Rwanda.International Journal of Social Economics, 36 (5), 608-625.

Pitt, M., and S. Khandker. (1998). The impact of group-based credit programs on poor households in Bangladesh: Does the gender of participants matter? Journal of political economy, 106 (5), 958-996.

Programa de Naciones Unidas para el Desarrollo - PNUD. (2005). Las microfinanzas en Argentina. Washington: 0NU.

Quibria, M.G. (2012). Microcredit and poverty alleviation: Can microcredit close the deal? No. UNU-WIDER Research Paper WP2012/78.

Rambabu, P.D.; and Y.P. Eswaran. (1994). Factors influencing attitude of the farmers towards farm credit. Agricultural Banker, 25. 
Reed, L.R. (2011). State of the microcredit summit campaign report 2011. Microcredit Summit Campaign. Washington DC.

Reinke, J. (1998). How to lend like mad and make a profit: A micro-credit paradigm versus the start-up fund in South Africa. The Journal of Development Studies, 34 (3), 44-61.

Roslan, A.; Z. Faudziah, Z. Mohd Saifoul, and M. Rahimah. (2007). Microfinance service for micro-enterprise: Good practices and performance of selected microfinance institutions in Malaysia. Journal of Yala Rajabhat University, 2 (1), 31-45.

Samba, R. (2013). La lutte contre la pauvreté par le microcrédit: Identification et analyse des termes de la demande. La Revue du Financier, 203, 35-51.

Sharma, M.; and M. Zeller. (1997). Repayment performance in group-based credit programs in Bangladesh: An empirical analysis. World Development, 25 (10), 1731-1742.

The Economist Intelligence Unit (2010). Microscopio global sobre el entorno de negocios para las microfinanzas. Recuperado de www.eiu.com

Van Bastelaer, T. (2002). Does social capital facilitate the poor's access to credit? Understanding and Measuring Social Capital: A Multidisciplinary Tool for Practitioners, 237-264.

Wooldridge, J. (2006). Introductory Econometrics. Thomson-South Western.

Zander, R. (1994). Barriers to credit access in rural Sri Lanka. Financial Landscapes Reconstructed: The Fine Art of Mapping Development. Boulder: Westview Press.

\section{Anexo 1. Ranking de la demanda potencial de microcréditos por aglomerados urbanos}

\begin{tabular}{clrrlrc}
\hline \multicolumn{3}{c}{ Ranking EDSA 2010} & & \multicolumn{3}{c}{ Ranking EDSA 2011} \\
\hline 1 & CONURBANO SUR & 210.428 & $21,2 \%$ & CONURBANO SUR & 307.060 & $23,9 \%$ \\
2 & CONURBANO 0ESTE & 130.041 & $13,1 \%$ & CÓRDOBA & 159.285 & $12,4 \%$ \\
3 & CÓRDOBA & 114.309 & $11,5 \%$ & CONURBANO NORTE & 142.575 & $11,1 \%$ \\
4 & CONURBANO NORTE & 83.750 & $8,4 \%$ & CONURBANO 0ESTE & 132.788 & $10,3 \%$ \\
5 & CAPITAL FEDERAL & 80.528 & $8,1 \%$ & CAPITAL FEDERAL & 92.516 & $7,2 \%$ \\
6 & MENDOZA & 67.498 & $6,8 \%$ & TUCUMÁN & 78.196 & $6,1 \%$ \\
7 & ROSARIO & 60.433 & $6,1 \%$ & ROSARIO & 70.611 & $5,5 \%$ \\
8 & TUCUMAN-TAFI VIEJ0 & 55.880 & $5,6 \%$ & MENDOZA & 59.308 & $4,6 \%$ \\
9 & MAR DEL PLATA & 45.785 & $4,6 \%$ & SALTA & 51.214 & $4,0 \%$ \\
10 & RESISTENCIA & 24.659 & $2,5 \%$ & MAR DEL PLATA & 43.831 & $3,4 \%$ \\
11 & LA RIOJA & 22.946 & $2,3 \%$ & RESISTENCIA & 38.053 & $3,0 \%$ \\
12 & SALTA & 22.462 & $2,3 \%$ & NEUQUEN & 35.569 & $2,8 \%$ \\
13 & SAN JUAN & 19.442 & $2,0 \%$ & SAN JUAN & 26.210 & $2,0 \%$ \\
& & & & & & Continúa
\end{tabular}




\begin{tabular}{|c|c|c|c|c|c|c|}
\hline \multirow[b]{2}{*}{14} & \multicolumn{3}{|c|}{ Ranking EDSA 2010} & \multicolumn{3}{|c|}{ Ranking EDSA 2011} \\
\hline & NEUQUEN-PLOTTIER-CIPOLLETTI & 14.455 & $1,5 \%$ & PARANÁ & 21.672 & $1,7 \%$ \\
\hline 15 & GOYA & 12.955 & $1,3 \%$ & GOYA & 16.328 & $1,3 \%$ \\
\hline 16 & SAN RAFAEL & 12.465 & $1,3 \%$ & SAN RAFAEL & 6.097 & $0,5 \%$ \\
\hline 17 & PARANÁ & 9.297 & $0,9 \%$ & ZARATE & 5.603 & $0,4 \%$ \\
\hline 18 & USHUAIA-RIO GRANDE & 4.540 & $0,5 \%$ & TIERRA DEL FUEGO & 329 & $0,0 \%$ \\
\hline 19 & ZARATE & 2.613 & $0,3 \%$ & LA RIOJA & - & $0,0 \%$ \\
\hline \multirow[t]{2}{*}{20} & COMODORO RIVADAVIA & - & $0,0 \%$ & COMODORO RIVADAVIA & - & $0,0 \%$ \\
\hline & Total & 1.636 .366 & $100 \%$ & Total País & 2.080 .187 & $100 \%$ \\
\hline
\end{tabular}

Fuente: elaboración propia con base en datos EDSA 2010-2011.

Anexo 1. Cuadro A.2.1 Resultados de regresiones Logit de la probabilidad de demandar un microcrédito productivo en 2011

\begin{tabular}{|c|c|c|c|c|c|}
\hline & Modelo Logit: & Coef. & SE & $z$ & $P(z)$ \\
\hline \multirow{2}{*}{ Préstamo } & Si, solicitó y lo obtuvo & 0,3913 & 0,3832 & 1,02 & $31 \%$ \\
\hline & Si, solicitó y no obtuvo & 0,7068 & 0,5186 & 1,36 & $17 \%$ \\
\hline Ciudad & Grandes (BA, GBA, CBA, ROS) & $-0,1017$ & 0,2388 & $-0,43$ & $67 \%$ \\
\hline Sexo & Femenino & $-0,5722$ & 0,2718 & $-2,11$ & $4 \%$ \\
\hline \multirow{2}{*}{ Edad } & Años & 0,0955 & 0,0627 & 1,52 & $13 \%$ \\
\hline & Años al cuadrado & $-0,0014$ & 0,0007 & $-1,89$ & $6 \%$ \\
\hline Estado civil & En pareja & $-0,1796$ & 0,2497 & $-0,72$ & $47 \%$ \\
\hline Educación & Secundaria completa & $-0,0903$ & 0,2909 & $-0,31$ & $76 \%$ \\
\hline \multirow{6}{*}{ Ocupación } & Cuentapropista & 2,6403 & 1,4500 & 1,82 & $7 \%$ \\
\hline & Profesional & 1,0705 & 1,0614 & 1,01 & $31 \%$ \\
\hline & Empleo público & 3,9425 & 1,0548 & 3,74 & $0 \%$ \\
\hline & Empleo privado & 3,9120 & 1,0225 & 3,83 & $0 \%$ \\
\hline & Empleo precario & 3,7129 & 1,0497 & 3,54 & $0 \%$ \\
\hline & Plan social con contraprestación & - & (omitted) & & \\
\hline Vivienda & Propietario & 0,4928 & 0,2514 & 1,96 & $5 \%$ \\
\hline Ingresos & Ingreso mensual & 0,0000 & 0,0000 & 0,25 & $80 \%$ \\
\hline \multirow{2}{*}{$\begin{array}{l}\text { Situación } \\
\text { laboral }\end{array}$} & Informal & 0,4653 & 0,3118 & 1,49 & $14 \%$ \\
\hline & Desocupado & 0,3045 & 0,5416 & 0,56 & $57 \%$ \\
\hline Bancarizado & Tiene tarjeta y cuenta bancaria & 0,1612 & 0,3512 & 0,46 & $65 \%$ \\
\hline Plan social & Recibe plan social & $-0,0527$ & 0,4294 & $-0,12$ & $90 \%$ \\
\hline Constante & & $-8,3676$ & 1,7264 & $-4,85$ & $0 \%$ \\
\hline
\end{tabular}




\begin{tabular}{llccc}
\hline \multicolumn{1}{c}{ Modelo Logit: } & Coef. & SE & z & P $(z)$ \\
\hline Pseudo-R2 & \multicolumn{3}{c}{0.0652} \\
\hline Test de Wald-significatividad global & Wald chi2 $(20)=80.77$ & Prob $>$ chi2 $=0.0000$ \\
\hline Observaciones & \multicolumn{3}{c}{2.441} \\
\hline
\end{tabular}

Fuente: elaboración propia con base en datos EDSA 2011.

Anexo 1. Cuadro A.2.2 Resultados de regresiones Logit de la probabilidad de demandar un microcrédito para vivienda en 2011

\begin{tabular}{|c|c|c|c|c|c|}
\hline & Modelo Logit: & Coef. & SE & z & $\mathrm{P}(\mathrm{z})$ \\
\hline \multirow{2}{*}{ Préstamo } & Si, solicitó y lo obtuvo & 0,58893 & 0,23309 & 2,53 & $1 \%$ \\
\hline & Si, solicitó y no obtuvo & $-0,24497$ & 0,44485 & $-0,55$ & $58 \%$ \\
\hline Ciudad & Grandes (BA, GBA, CBA, ROS) & $-0,04594$ & 0,15976 & $-0,29$ & $77 \%$ \\
\hline Sexo & Femenino & 0,16857 & 0,18487 & 0,91 & $36 \%$ \\
\hline \multirow{2}{*}{ Edad } & Años & 0,07081 & 0,03728 & 1,90 & $6 \%$ \\
\hline & Años al cuadrado & $-0,00101$ & 0,00043 & $-2,32$ & $2 \%$ \\
\hline Estado civil & En pareja & 0,35939 & 0,20110 & 1,79 & $7 \%$ \\
\hline Educación & Secundaria completa & 0,06339 & 0,18984 & 0,33 & $74 \%$ \\
\hline \multirow{6}{*}{ Ocupación } & Cuentapropista & 2,83061 & 0,65400 & 4,33 & $0 \%$ \\
\hline & Profesional & $-0,52587$ & 0,51860 & $-1,01$ & $31 \%$ \\
\hline & Empleo público & 2,73424 & 0,49965 & 5,47 & $0 \%$ \\
\hline & Empleo privado & 2,82508 & 0,45796 & 6,17 & $0 \%$ \\
\hline & Empleo precario & 2,94215 & 0,47634 & 6,18 & $0 \%$ \\
\hline & Plan social con contraprestación & 1,42375 & 1,12938 & 1,26 & $21 \%$ \\
\hline Vivienda & Propietario & $-0,08929$ & 0,18178 & $-0,49$ & $62 \%$ \\
\hline Ingresos & Ingreso mensual & $-0,00003$ & 0,00004 & $-0,61$ & $54 \%$ \\
\hline \multirow{2}{*}{$\begin{array}{l}\text { Situación } \\
\text { laboral }\end{array}$} & Informal & 0,21660 & 0,20265 & 1,07 & $29 \%$ \\
\hline & Desocupado & 0,31772 & 0,36316 & 0,87 & $38 \%$ \\
\hline Bancarizado & Tiene tarjeta y cuenta bancaria & 0,07007 & 0,22815 & 0,31 & $76 \%$ \\
\hline Plan social & Recibe plan social & $-0,22428$ & 0,29159 & $-0,77$ & $44 \%$ \\
\hline \multicolumn{2}{|l|}{ Constante } & $-6,04851$ & 0,90819 & $-6,66$ & $0 \%$ \\
\hline \multicolumn{2}{|l|}{ Pseudo-R2 } & \multicolumn{4}{|c|}{0.065} \\
\hline \multicolumn{2}{|c|}{ Test de Wald-significatividad global } & \multicolumn{2}{|c|}{ Wald $\operatorname{chi} 2(20)=40.43$} & \multicolumn{2}{|c|}{ Prob $>$ chi $2=0.0029$} \\
\hline \multicolumn{2}{|l|}{ Observaciones } & \multicolumn{4}{|c|}{2.423} \\
\hline
\end{tabular}

Fuente: elaboración propia con base en datos EDSA 2011. 